\title{
A comunicação nas encruzilhadas da Esfinge, de Hermes, Mercúrio, Exu e Maria Padilha: ditos, não-ditos, interditos e mal-entendidos*
}

\section{RESUMO}

A presente comunicação se encontra nas encruzilhadas das ciências humanas (antropologia, filosofia, história e sociologia) com as ciências sociais aplicadas (comunicação), as letras (portuguesas, espanholas e francesas) e as artes (canto, dança, dramaturgia, teatro e ópera). Trata-se da perspectiva transdisciplinar e gaia da etnocenologia (Duvignaud, 1996) ${ }^{1}$, que se situa, por sua vez, em diversas encruzilhadas, entre as artes e as ciências (no âmbito destas, entre as ciências do espírito e as da natureza, Geistwissenchaften $X$ Naturwissenchaften), entre os objetos do real e do ideal, do material e do espiritual e entre os objetos que possuem e aqueles que não possuem existência.

\section{PALAVRAS-CHAVE}

encruzilhadas da comunicação

etnocenologia

ditos, interditos e mal-entendidos

\section{ABSTRACT}

This communication is at the crossroads of the human sciences (anthropology, philosophy, history and sociology) with the applied social sciences (communication), languages (Portuguese, Spanish and French) and the arts (music, dance, drama, theater and opera ). It is the prospect of disciplinary and gaia ethnoscenology (DUVIGNAUD, 1996), which is in turn in various crossroads between the arts and sciences (in the latter, between the sciences of mind and nature, Geistwissenchaften X Naturwissenchaften), among the objects of the real and the ideal, the material and the spiritual and the objects that have and those who have no existence.

\section{KEY WORDS}

crossroads of communication

ethnoscenology

said, banned e misunderstandings
De um modo geral, as encruzilhadas (daí, do mundo) são loci da comunicação, das línguas, das feiras temporárias e permanentes, dos mercados, das cidades, dos teatros edificados e das profissões das artes do espetáculo. Aí se encontra a Esfinge (e suas charadas mortais), Tirésias (o que vê mais quer os demais, sem nada ver, tão importante para theorein e para theatrum ${ }^{2}$ ), Hermes (o que nos legou o poder da interpretação dos textos sagrados e o grande problema da traduzir e trair; na expressão italiana: traduttore traditore).

Por aí vem Dionísio (o estrangeiro, que será patrono do teatro e da milenar questão sobre as distinções entre cultura e civilização) e por aí circulam Mercúrio (o patrono romano do comércio), Exu (a entidade gege nagô, do trato humano com a natureza e o sobrenatural), todos os mensageiros e tricksters (responsáveis pelos bem entendidos e pelos malentendidos, esses os que descontrolam) e todos os diabos e fadas (que desencantam e encantam). Aí, nas encruzilhadas, lugares de encontros e desencontros, também, se constróem os monumentos memoriais e a sinalização de tráfego (que tentam tudo controlar) e reside, simultaneamente, o perigoso e o maravihoso.

Já em outro registro, a encruzilhada é uma representação perfeita do corpo humano (do que está dentro com o que está fora) e do cosmos, da mesma maneira que as naus e caravelas da Renascença e do Barroco são verdadeiras encruzilhadas ambulantes, inclusive muitas bem maiores, em população, que muitas das cidades de sua época, ancoradas, assemelhadas e representadas nos palcos dos teatros. De fato, a arquitetura naval e teatral, renascentista e barroca, é a mesma, de pau e corda.

Encruzilhadas são a casa da angústia existencialista da escolha do caminho a tomar ou da imobilidade. Mover-se? Para onde? Para trás? Para a frente? Por qual dos caminhos?

Aí a rotina ordinária convive com os acontecimentos extraordinários. Daí serem sua melhor representação, os teatros, encruzilhadas de dança, teatro, ópera, música, magia, diversão, sobrevivência e vida das artes do espetáculo! Aí se cruzam pessoas de todo tipo, inclusive marginalizados que só aí têm lugar. Aí e em encruzilhadas vizinhas (bares, prostíbulos, etc), formaram-se alguns dos mais importantes ícones de povos do Atlântico Negro: o tango argentino, o candomble uruguaio, o samba brasileiro, o fado português, o flamenco andaluz e o jazz norteamericano! 


\section{Mulheres por um fio}

É nessa perspectiva, da etnocenologia, que se inscreve o projeto de pesquisa, da área de artes, patrocinado em parte pelo $\mathrm{CNPq}$, para o período de março de 2008 a fevereiro de 2011, Mulheres por um fio: inferno, purgatório e paraíso no Atlântico Negro. Trata-se da criação e experimentação cênica de um corpus de dados históricos, poéticos, musicais e teatrais sobre os fenômenos de transformação de uma personalidade espanhola do século XIV, Doña María de Padilla, na entidade dos cultos afro-brasileiros dos séculos XX e XXI Maria Padilha.

Órfã e nobre castelhana Mari Díaz (1333/1361), "mujer de buen linaje e fermosa e pequeña de cuerpo e de buen entendimiento", segundo Ayala, cronista da época (1991, p. 263). Passa a ser conhecida como Doña María de Padilla, em 1352, ao se transformar em favorita do rei D. Pedro I de Castela (1334/1369), único filho legítimo de dois primos-irmãos, D. Alfonso XI e D. Maria, princesa de Portugal, irmã do rei D. Pedro I de Portugal (o que fez de sua amada e assassinada Inês "tão linda" (1320/ 1355) rainha depois de morta (1360). A "fermosíssima" D. Maria de Portugal e a "linda" Inês são cantadas por Camões em Os Lusíadas (canto III, estrofes 102 a 105; canto III, estrofes 118 a 135).

\section{Encruzilhadas são a casa da} angústia existencialista da escolha do caminho a tomar ou da imobilidade. Mover-se? Para onde? Para trás? Para a frente? Por qual dos caminhos?

Doña María de Padilla (1333/ 1361) tem com D. Pedro I de Castela quatro filhos, todos infantes reais legitimados: um varão, morto criança e três meninas, uma que vive e morre freira e duas que se casam com nobres ingleses. Ela funda em 1353 o Convento de Astudillo, abençoado pelo Papa Inocencio VI, em 1354, que pensa se tratar de uma penitência dos amantes adúlteros, mas que, pouco depois, os excomunga. Morta em 1361, provavelmente de peste, Doña María de Padilla é declarada Rainha em 1362, pelo rei D. Pedro I de Castela e pelas autoridades católicas de Sevilha (dois anos após Inês ter sido declarada Rainha de Portugal).

A pedido de sua mãe, D. Maria de Portugal, D. Pedro I de Castela manda matar a amante de seu pai. Também manda matar três de seus 10 meio-irmãos, a princesa francesa sua esposa legítima Blanche de
Bourbon, vários nobres e religiosos e sua própria mãe D. Maria! Contra nobres e a Igreja, alia-se a mouros e judeus. Morto por um de seus meio-irmãos, fica conhecido como O Cruel, depois O Justiceiro, graças a sua tataraneta e de D. Padilla: D. Isabel a Católica. Além dos quatro filhos com D. Padilla, tem cinco com outras três mulheres. Casa-se formalmente com Blanche de Bourbon (1353) e Joana de Castro (1354), irmã de Inês de Portugal, mas com elas passa pouquíssimo tempo, voltando sempre para Doña María de Padilla, para quem constrói boa parte do moçárabe Alcazar de Sevilha e com quem convive de 1352 a 1361 (Mèrimèe, 1961).

Parte dessa história sangrenta vira romance de vingança contra D. Pedro e D. María, que teria transformado em cobra um cinto dado de presente pela rainha Blanche de Bourbon a D. Pedro, com a ajuda de um feiticeiro judeu (Ros, 2003):

\section{Doña María de Padilla \\ La cinta hubiera en su mano \\ Dió la en poder de un judio \\ Que era magico e sábio \\ Puso el ella tales cosas \\ Que al Rey mucho han espantado \\ Culebra le ha semajado}

O romancero viejo espanhol se espalha pela península ibérica, que, de 1580 a 1640, era uma só Espanha, onde a Inquisição passa a registrar invocações à Padilla. Algumas dessas invocações chegam ao Brasil, através das "feiticeiras" expulsas de Portugal, já antes do século XVIII:

Eu te conjuro vinagre, pimenta e enxofre em nome de Pedro, com três da padaria, três da cutilaria, três do açougue, três do terreiro, três do haver do peso, todos três, todos seis, todos nove se ajuntarão no coração de Pedro entrarão, se mais são, ou menos são, 56 diabos se ajuntarão, à torre do Primão se treparão, nove varas de amor apanharão, na mó de Caifás as aguçarão, no coração de Pedro as cravarão, que não possa estar, nem sossegar, até comigo não vir estar; Dona Maria de Padilha com toda a quadrilha me trazeis Pedro [...]

Barrabás, Satanás, Caifás, Maria Padilha com toda a sua quadrilha, Maria da Calha com toda a sua canalha, cavalo marinho que com pressa os traga pelo caminho.

Hoje, em Sevilha, onde, assim como em Astudillo, ao lado do Convento das Irmãs Clarissas, o nome de D. María de Padilla designa um importante rua. A placa que aparece nesta imagem que ora lhes exibo encontra-se no muro da Universidade de Sevilha, onde funcionou a antiga fábrica de tabacos, na qual trabalhava a famosa personagem de Mérimée Carmen. Na novela original, Carmen também invoca D. María 
de Padilla, logo antes de ser morta por Don José, que, assim, narra esse episódio:

[...] J'espérais presque que Carmen se serait enfuie; elle aurait pu prendre mon cheval et se sauver... mais je la retrouvai. Elle ne voulait pas qu'on pût dire que je lui avais fait peur. Pendant mon absence, elle avait défait l'ourlet de sa robe pour en retirer le plomb. Maintenant, elle était devant une table, regardant dans une terrine pleine d'eau le plomb qu'elle avait fait fondre, et qu'elle venait d'y jeter. Elle était si occupé de sa magie qu'elle ne s'aperçut pas d'abord de mon retour. Tantôt elle prenait un morceau de plomb et le tournait de tous les côtés d'un air triste, tantôt elle chantait quelqu'une de ces chansons magiques où elles invoquent Marie Padilla, la maîtresse de Don Pédro [...] (Mèrimèe, 1945, p. 180). ${ }^{4}$

Carmen contrabandeou bens materiais e amorosos entre Sevilha e Ronda, onde há um museu (turístico mais que etnográfico) para a bruxaria, que, no entanto, silencia sobre a Padilla!

\section{Aí e em encruzilhadas vizinhas (bares, prostíbulos, etc), formaram-se alguns dos mais importantes ícones de povos do Atlântico Negro: o tango argentino, o candomble uruguaio, o samba brasileiro, o fado português, of flamenco andaluz $e$ o jazz norte-americano!}

A partir do final de 2007, e já realizando as pesquisas preliminares para o projeto que começaria a ser, parcialmente, financiado pelo CNPq em março de 2008, a convite de ex-alunos, criei a personagem de uma mulher por um fio. Tratava-se de uma mulher madura, frustrada no amor, professora de canto e aficionada pela poesia e por óperas, que invocava, em suas quatro cenas de um espetáculo, a Padilha . Nesse processo, usando como inspiração a personagem famosa, mais um das encarnações da Padilla, que cantava, em sua primeira entrada na popularíssima ópera, com música de Georges Bizet e libreto de Henri Meilhac e Ludovic Halévy, o amor como um pássaro selvagem e indomável, que ninguém consegue domesticar, a
Habanera L'amor est un oiseau rebelle, propus a seguinte paródia:

Oh senhora Maria Padilha

Minha alma venha alegrar

Traga paz aqui para sua filha

Que só canta para não chorar

Amor Amor Amor Amor

O amor é mais

Mais que um poema

Também no romantismo francês, além de Mérimée, Victor Hugo se interessou pelo imaginário espanhol, tendo escrito um poema, em 1828, sobre uma certa freira chamada Doña Padilla del Flor, que é castigada pela fúria divina dentro de uma igreja católica juntamente com seu amado, sendo ambos fulminados por um repentino e inusitado raio. Georges Brassens faria desse poema uma popular canção francesa em 1956.

Venez, vous dont l'œil étincelle

Pour entendre une histoire encor

Approchez: je vous dirai celle

De doña Padilla del Flor

Elle était d'Alanje, où s'entassent

Les collines et les halliers

Enfants, voici des bœufs qui passent

Cachez vos rouges tabliers

Il est des filles à Grenade

Il en est à Séville aussi

Qui, pour la moindre sérénade

A l'amour demandent merci

Il en est que parfois embrassent

Le soir, de hardis cavaliers

Enfants, voici des bœufs qui passent

Cachez vos rouges tabliers

Ce n'est pas sur ce ton frivole

Qu'il faut parler de Padilla

Car jamais prunelle espagnole

D'un feu plus chaste ne brilla

Elle fuyait ceux qui pourchassent

Les filles sous les peupliers

Enfants, voici des bœufs qui passent

Cachez vos rouges tabliers

Or, la belle à peine cloîtrée

Amour en son cœur s'installa

Un fier brigand de la contrée

Vint alors et dit: "Me voilà!"

Quelquefois les brigands surpassent

En audace les chevaliers

Enfants, voici des bœufs qui passent

Cachez vos rouges tabliers

Or quand, dans la nef descendue

La nonne appela le bandit

$\mathrm{Au}$ lieu de la voix attendue

C'est la foudre qui répondit 
Dieu voulu que ses coups frappassent

Les amants par Satan liés

Enfants, voici des bœufs qui passent

Cachez vos rouges tabliers

O sexo selvagem e irracional é, aí, mais uma vez, associado à mulher que não cumpre sua obrigação religiosa. Mas, na Europa e, sobretudo, na própria Espanha, o teatro (Donizetti, 1845; Villaespesa, 1913) e ensaios históricos reconstruiriam o imaginário relativo a Doña Maria, a partir das crônicas de Ayala, chamando-a de "dulce y equillibrada castillana" (Ferrer, 1975) e de "angel bueno de Pedro el cruel" (Ros, 2003), fazendo dela uma vítima do rei cruel e distanciando-a, assim, do que viria a ser a Maria Padilha brasileira, mais próxima do que construíram o romancero, a Inquisição e a tradição romântica francesa.

A mazona (sem coração? sem o seio do coração? amazona?) Maria Padilha brasileira é a rainha das encruzilhadas e de todas as pomba-giras, entre as quais se destaca a Nega de Um Peito Só.

\section{Personagem de diversos folhetos de cordel, a mazona Nega De Um Peito Só aparece brigando com Lampião, no folheto 0 encontro de Lampião com a Negra Dum Peito Só, de José Costa Leite}

No dizer de Monique Augras (2001, p. 293), trata-se de uma "diablesa sedutora y terrible", "permanencia en el imaginario social de una visión amenazadora de la mujer que afirma su sexualidad".

Para a etnolinguista Yeda Pessoa de Castro, para quem Maria Padilha é uma "entidade muito popular e muito temida, tida como Exu, fêmea, ladrona, maledicente e escrava de Oxum" (Castro, 2001, p. 277), pomba-gira é uma palavra de origem banto, que designa um substantivo feminino:

Exu-fêmea, variante de Bambojira (entidade congoangola), reparte com ele o controle das encruzilhadas e caminhos, e exerce influência sobre os namoros, noivados e casamentos desfeitos. É representada na figura de uma mulher sedutora, branca, de cabelos longos e louros, tida como protetora das prostitutas (Castro, 2001, p. 317).

Para Carlos Caroso e Núbia Rodrigues (2004, p. 336), por conta de pesquisa de campo realizada na Bahia, entre as numerosas variantes de exus se encontram as pomba-giras, as fêmeas "Maria Padilha" (a primeira da lista que apresentam) e a "Nega de Um Peito Só" (a última personagem feminina da mesma lista).

Personagem de diversos folhetos de cordel, a mazona Nega De Um Peito Só aparece brigando com Lampião, no folheto O encontro de Lampião com a Negra Dum Peito Só, de José Costa Leite (s.d.), que já adaptei para o teatro em diversas ocasiões, a mais recente em 2008 (Bião, 2009). Aí são bem perceptíveis os ecos da Inquisição e dos preconceitos sexista, machista e racista, dessa já longa tradição, na qual, no lugar de judeus e ciganos, aparecem os negros. Aqui, teatralmente, mais uma vez, trechos desse folheto, começando com a preparação de um feitiço:

Três canelas de defunto

3 pés de capim assu

3 galhos de pinhão roxo

3 escamas de mussu

3 galhos de mussambê

3 bicos de zabelê

e 3 penas de jacu.

Quatro rabos de arraias

4 pés de seriema

4 maracais de cobra

4 folhas de jurema

4 caveiras de gente

4 dentes de serpente

e 4 penas de ema.

Cinco bicos de socó

5 costelas e um papo

5 folhas de maconha

5 cabelos de sapo

5 grilos encangados

5 vidros preparados

do suco do jenipapo.

A oração do sapo-seco

ela rezou com cautela

benzeu com a mão esquerda

e depois botou na panela

o suco de um pepino

a raspa do som do sino

e o leite da favela.

Rezou mais a oração

da cabra preta falada

e a de São Cipriano

e foi com a panelada

muito contente e faceira

numa noite de sexta-feira

botar numa encruzilhada...

E fala pra Lampião:

- Por você eu vivo louca

já que a hora é chegada

lave a boca bem lavada

e venha beijar minha boca! 
-Te dana!

negra feia desgraçada

não gosto de negra moça

quanto mais velha e pelada

- Êh coisa racista danada!

-Ela balançava o peito

por lado de Lampião dizendo:

-Quer ou não quer?

deixas de cavilação

eu vim pra você mamar

você deve aproveitar

esta boa ocasião.

- Botou o peito pra fora

que parecia uma jaca

Lampião se afastou

e pegou no cabo da faca

dizendo:

-Daí pra trás

- Rapaz você está feito vaca?

- A negra deu uma dentada

na venta de Lampião!

Depois um galo cantou

e ela ficou sem ação.

$\mathrm{Na}$ vista dele, despiu-se,

deu um estouro e sumiu-se

sem deixar sinal no chão.

E assim continuam as pomba-giras voando pelas encruzilhadas, sumindo e reaparecendo. Elas se encontram no Rio de Janeiro, em São Paulo, Recife e em Salvador, no Brasil. Mas as Padilhas também se encontram no Uruguai, na Argentina e na internet, onde, por encomenda, pode-se adquirir uma "Maria Padilha da Calunga $40 \mathrm{~cm}$ - Pintada con acrílico y barniz - patinada al oleo, acabado nacarado estrictamente a pedido."

A rainha das encruzilhadas não bebe cachaça, só bebe champanhe, não fuma charuto, só fuma cigarrilha ou cigarro com piteira, aprecia as rosas vermelhas, uma boa dança e um bom "ponto" convidando-lhe para "comer".

E assim se dá a comunicação nas encruzilhadas, fazendo-se teatro e teoria, como eu tentei obrar aqui, nesta minha comunicação. Assim, nas encruzilhadas das charadas mortais da Esfinge, da capacidade tradutora (traidora?) de Hermes, dos vôos comerciais de Mercúrio, dos ditos, não-ditos, interditos e malentendidos de Exu e de Maria Padilha, recriando imaginários, usando todos os meios estéticos de propaganda política e ideológica, de gozo artístico poético musical e teatral e fazendo-se necessidade absoluta do extraordinário no cotidiano!

E assim continuam as pombagiras voando pelas encruzilhadas, sumindo e reaparecendo. Elas se encontram no Rio de Janeiro, em São Paulo, Recife e em Salvador, no Brasil. Mas as Padilhas também se encontram no Uruguai,
na Argentina e na internet

Salve Pomba-gira Maria Padilha. Rainha das sete encruzilhadas!

Muito obrigado! maAmEcos

NOTAS

* Trabalho apresentado no X Seminário Internacional de Comunicação, PUCRS, novembro de 2009

1 Jean Duviganud presidiu, em 1995, o colóquio internacional, promovido pela UNESCO, a Maison des Cultures du Monde e a Université Paris VIII Vincennes à Saint Denis, no qual foi lançada a proposta da etnocenologia.

2 Alfred Schütz nos legou um ensaio emblemático (1987), sobre o complexo humano de Tirésias (que permite a vida em coletividade), tratando tanto do âmbito teórico quanto teatral. Já a importância desse personagem mítico para o teatro é sobejamente conhecida, desde a trilogia tebana.

3 Este é um trecho de um dos 20 romances históricos, que compõem o Ciclo de D. Pedro, produzidos no século XV. Sobre o romancero: Pidal, 1968; Roig, 2007; Diaz-Mas, 2001. Sobre este romance, em particular: Souza, 2009; Meyer, 1993.

4 Esta pista me foi sugerida pelo antropólogo pernambucano Roberto Motta em 1990, em Paris. Ver Motta, 1988; 1990; 1995.

5 O espetáculo O Pique dos Índios ou A Espingarda de Caramuru, com texto de Haydil Linhares e direção de Vinício Oliveira Oliveira, foi produzido pela A Outra Companhia de Teatro, no Teatro Vila Velha, 
em Salvador BA, com temporada de 16 apresentações, em março 2008.

6 Esta pista me foi sugerida pela aluna franco-brasileira, de nosso Programa de Pós-Graduação em Artes Cênicas da Universidade Federal da Bahia, Étoile Santos da Silva, no segundo semestre de 2008, em sala de aula.

\section{REFERÊNCIAS}

AUGRAS. Monique R. María Padilla, reina de la magia. Revista Española de Antropología Americana, Madrid, n. 31, p. 293-319, 2001.

AYALA, Pero López. Crónicas. Barcelona: Planeta, 1991.

BIÃO, Armindo. GIPE-CIT canta Padilha. Revista Repertório Teatro E Dança, Salvador, n 12, p. 55-77, 2009.

CAROSO, Carlos; RODRIGUES, Núbia. Exus no Candomblé de Caboclo. In: PRANDI, Reginaldo (Org.). Encantaria brasileira: o livro dos mestres, caboclos e encantados. Rio de Janeiro: Pallas, 2004.

CASTRO, Yeda Pessoa de. Falares africanos na Bahia: um vocabulário afro-brasileiro. Rio de Janeiro: Topbooks, 2001.

DÍAZ-MAS, Paloma (Ed.). Romancero. Barcelona: 2001.

DUVIGNAUD, Jean. Une piste nouvelle. In: Internationale de l'Imaginaire - nouvelle. (série $\mathrm{n}$. 5). Paris: MCM/ Babel, 1996.

FERRER, Casilda Ordóñez. María de Padilla: esa dulce y equilibrada castellana. Palencia: Publicaciones de la Institución Tello Téllez de Meneses, 1975.

LEITE, José Costa. O encontro de Lampião com a Negra Dum Peito Só. [Folheto de cordel]. Condado, PE: [s. 1.], [s. n], [s. d.].

Maria Padilla: Melodrama em 3 actos com música de DONIZETTI, para se representar no R. T. São Carlos. Lisboa: Typographia de P. A. Borges, 1845, 79 p.

MÈRIMÈE, Prosper. Histoire de Don Pèdre Ier, roi de Castille. Paris: Didier, 1961.

MÈRIMÈE, Prosper. Carmen (1845) précedée de La Vénus d'Ille et de Colomba. Monaco: Richer, 1945.
MEYER, Marlyse. Maria Padilha e toda sua quadrilha: de amante um rei de Castela a Pomba-Gira de Umbanda. São Paulo: Duas Cidades, 1993.

MOTTA, Roberto. O Sexo e o Candomblé: Repressão e Simbolização. In: PITTA, Danielle Perin Rocha; MELLO, Rita Maria Costa (Org.). Vertentes do Imaginário. Recife: EDUFPE, 1995.

MOTTA, Roberto. Transe du corps et transe de la parole dans les religions syncrétiques du Nordest du Brésil. Cahiers de l'Imaginaire. n. 5; n. 6. Paris: L'Harmattan, p. 47-62, 1990.

MOTTA, Roberto. Transe, Possessão e Exxtase nos Cultos Afro-brasileiros do Recife. In: CONSORTE, Josildeth Gomes; COSTA, Márcia Regina da (Org.). Religião, politica, identidade. São Paulo: EDUC, p. 109-120, 1988.

PIDAL. Ramón Menéndez. Romancero hispánico (hispano-portugués, americano y sefardí): teoría y historia. Madrid: Espasa-Calpe, 1968.

ROIG, Mercedes Díaz (Ed.). El romancero viejo. 23 $3^{\mathrm{a}}$. ed. Madrid: Cátedra, 2007.

ROS, Carlos. Doña María de Padilla: el ángel bueno de Pedro el Cruel. Sevilla: Castillejo, 2003.

SCHÜTZ, Alfred. Tirésias ou notre connaissance des événements futurs. In: NOSCHIS-GILLIÉRON, Anne (Tradução de: ). MAFFESOLI, Michel (Pref.). Le chercheur et le quotidien. Paris: Méridiens Klincksieck, 1987.

SOUZA, Laura de Mello e. O diabo e a terra de Santa Cruz: Feitiçaria e religiosidade popular no Brasil colonial. 2. ed. São Paulo: Companhia das Letras, 2009.

VILLAESPESA, Francisco. Doña Maria de Padilla. Madrid: Renacimiento, 1913.

Sites consultados

http:/ / www.etnocenologia.org

http://www.revistarepertorioteatroedanca.tea.ufba. br/index.html 